EGU21-12839, updated on 31 Mar 2021

https://doi.org/10.5194/egusphere-egu21-12839

EGU General Assembly 2021

(c) Author(s) 2021. This work is distributed under

the Creative Commons Attribution 4.0 License.

\title{
Quantifying Uncertainty through 3D Geological Modeling for Carbon Capture Utilization and Storage in the Unayzah Formation in Saudi Arabia
}

Sofia Mantilla Salas, Miguel Corrales, Hussein Hoteit, Abdulkader Alafifi, and Alexandros Tasianas Ali I. Al-Naimi Petroleum Engineering Research Center, ANPERC, King Abdullah University of Science and Technology, KAUST, Thuwal, Saudi Arabia

The development of Carbon Capture Utilization and Storage (CCUS) technology paired with existing energy systems will facilitate a successful transition to a carbon-neutral economy that offers efficient and sustainable energy. It will also enable the survival of multiple and vital economic sectors of high-energy industries that possess few other options to decarbonize. Nowadays, just about one-ten-thousandth of the global annual emissions are being captured and geologically-stored, and therefore with today's emission panorama, CCS large-scale deployment is more pressing than ever. In this study, a 3D model that represents the key reservoir uncertainties for a CCUS pilot was constructed to investigate the feasibility of CO2 storage in the Unayzah Formation in Saudi Arabia. The study site covers the area of the city of Riyadh and the Hawtah and Nuayyim Trends, which contain one of the most prolific petroleum-producing systems in the country. The Unayzah reservoir is highly stratified and it is subdivided into three compartments: the Unayzah C (Ghazal Member), the Unayzah B (Jawb Member), and the Unayzah A (Wudayhi and Tinat Members). This formation was deposited under a variety of environments, such as glaciofluvial, fluvial, eolian, and coastal plain. Facies probability trend maps and well log data were used to generate a facies model that accounted for the architecture, facies distribution, and lateral and vertical heterogeneity of this high complexity reservoir. Porosity and predicted permeability logs were used with Sequential Gaussian Simulation and co-kriging methods to construct the porosity and permeability models. The static model was then used for $\mathrm{CO} 2$ injection simulation purposes to understand the impact of the flow conduits, barriers, and baffles in $\mathrm{CO} 2$ flow in all dimensions. Similarly, the $\mathrm{CO} 2$ simulations allowed us to better understand the $\mathrm{CO} 2$ entrapment process and to estimate a more realistic and reliable CO2 storage capacity of the Unayzah reservoir in the area. To test the robustness of the model predictions, geological uncertainty quantification and a sensitivity analysis were run. Parameters such as porosity, permeability, pay thickness, anisotropy, and connectivity were analyzed as well as how various combinations between them affected the $\mathrm{CO} 2$ storage capacity, injectivity, and containment. This approach could improve the storage efficiency of $\mathrm{CO} 2$ exceeding $60 \%$. The analyzed reservoir was found to be a promising storage site. The proposed workflow and findings of the static and dynamic modeling described in this publication could serve as a guideline methodology to test the feasibility of the imminent upcoming pilots and facilitate the large-scale deployment of this very 
promising technology. 